\title{
Household use of biomass fuel, especially traditional stove is associated with childhood wheeze and eczema: a cross sectional study of rural communities in Kandy, Sri Lanka
}

\author{
Olivia Lall $^{1}$, Gayan Bowatte ${ }^{1}$, Samath Dharmaratne ${ }^{2}$, Adrian Lowe ${ }^{1}$, Alicia Vakalopoulos ${ }^{1}$, \\ Isabella Ambrose ${ }^{1}$, Pasan Jayasinghe ${ }^{3}$, Duminda Yasaratne ${ }^{2}$, Jane Heyworth ${ }^{4}$, and \\ Shyamali Dharmage ${ }^{1}$ \\ ${ }^{1}$ The University of Melbourne School of Population and Global Health \\ ${ }^{2}$ University of Peradeniya Faculty of Medicine \\ ${ }^{3}$ Ministry of Health, Central Province, Kandy, Sri Lanka \\ ${ }^{4}$ The University of Western Australia School of Population and Global Health
}

May 4, 2021

\begin{abstract}
Background: The majority of households in low- and middle-income countries (LMICs) rely on biomass fuel for daily cooking. Studies investigating the association between early life exposure to household air pollution and health outcomes in children in LMICs have been limited. This study aimed to investigate the effects of use of biomass fuel for cooking and different types of stoves on wheeze and allergies in children of rural Sri Lankan communities. Methods: A cross-sectional study was conducted on 452 children aged 5 years and younger in Kandy, Sri Lanka. A questionnaire was administered to mothers to gather information about use of biomass fuel and respiratory and allergic outcomes in children. The associations between biomass fuel and outcomes were analysed using logistic regression models adjusting for potential confounders. Results: Use of biomass fuel for cooking was associated with increased risk of childhood wheeze $(\mathrm{aOR}=2.38 ; 95 \% \mathrm{CI} 1.08-5.27)$ and eczema $(\mathrm{aOR}=4.49 ; 95 \% \mathrm{CI} 1.40-14.38)$ compared with households that used clean fuel (liquid petroleum gas (LPG), electricity and/or biogas). Among households that used biomass fuel, use of traditional biomass stoves was associated with higher risk of childhood wheeze (aOR=3.24; 95\% CI 1.28-8.20), allergic rhinitis ( $\mathrm{aOR}=3.08$; 95\% CI 1.34-7.04) and eczema ( $\mathrm{aOR}=7.96 ; 95 \%$ CI 2.35-26.93) compared with households that used clean stoves. Conclusion: Children living in households that used biomass fuel, especially traditional biomass cookstoves, were at higher risk of wheeze and allergic outcomes. Access to affordable clean energy sources may help to improve health of rural LMICs through reduction of air pollution.
\end{abstract}

\section{Hosted file}

HAP_and_wheeze_rhi_eczema_SL_study_copy.pdf available at https://authorea.com/users/ 411750/articles/520665-household-use-of-biomass-fuel-especially-traditional-stoveis-associated-with-childhood-wheeze-and-eczema-a-cross-sectional-study-of-ruralcommunities-in-kandy-sri-lanka

\section{Hosted file}

tables.pdf available at https://authorea.com/users/411750/articles/520665-household-useof-biomass-fuel-especially-traditional-stove-is-associated-with-childhood-wheeze-andeczema-a-cross-sectional-study-of-rural-communities-in-kandy-sri-lanka

\section{Hosted file}


Figure.pdf available at https://authorea.com/users/411750/articles/520665-household-useof-biomass-fuel-especially-traditional-stove-is-associated-with-childhood-wheeze-andeczema-a-cross-sectional-study-of-rural-communities-in-kandy-sri-lanka 